\title{
Assessment of Knowledge Sharing Practice in Dashen Bank Share Company of Ethiopia
}

\author{
Demmelash Abate Garbado \\ Lecturer in Department of Information systems, School Of informatics \\ Wolaita Sodo University, Ethiopia
}

\begin{abstract}
The major purpose of this study was to assess the knowledge sharing practice of the employees of Dashen Bank Share Company of Ethiopia. To this end, data were collected from a randomly selected 165 employees working in fifteen branches that found in Addis Ababa. In order to collect the relevant information, the researcher designed a self-administered questionnaire and semi-structured interview instruments traced on miscellaneous literature reviews. Both descriptive and inferential statistical analyses were employed appropriately for analyzing the quantitative data obtained. Thus, descriptive statistics such as frequency, mean and standard deviation, and inferential statistics such as t-test, ANOVA, post hoc comparisons, multiple correlations and multiple regressions were employed appropriately to analyze the quantitative data. Regarding the qualitative analysis, detailed description of qualitative data, obtained through semi-structured interview, was made. The finding revealed a statistically significant difference in employees' knowledge sharing practice with regard to their age, sex, educational status and work experience. Except educational status, knowledge sharing practice was negatively and significantly related with employees' age, sex, and work experience. Moreover, $16.1 \%$ of the variance in employees' knowledge sharing practice was accounted by the demographic variables of age, sex, educational status and work experience. The most prominent factors found to influence the knowledge sharing practices of Dashen Bank were scarcity of Information Technology infrastructures, lack of time, and lack of formal and informal awareness creating activities, lack of interaction among the staff members and poor physical work environment and office layouts. Thus, unless there is an environment of work where these influential factors are eased, the organizations' culture of knowledge sharing could not be improved to the extent it is expected to be. Besides, among the four modes of the SECI models of knowledge sharing, combination was found to be a widely practiced mode of knowledge sharing. Thus, in order to have a better environment of knowledge sharing practices, focusing on the socialization, internalization, externalization and combination modes together seems inevitable. Finally, the researcher recommends other researchers to conduct further study on the area both in depth and breadth.
\end{abstract}

Keywords: Dashen Bank, Share Company, Knowledge Sharing

DOI: $10.7176 / \mathrm{IKM} / 11-2-01$

Publication date:March $31^{\text {st }} 2021$

\section{INTRODUCTION}

\subsection{Background of the Study}

The modern world is characterized by dynamic and continuous technological advancement; and in order to cope with this change and to survive, organizations must become more flexible and open their door for change. Since the 1950s, a central question in international development has been how knowledge can best be generated, mobilized, made available, applied and adapted to improve the human condition (IFAD, 2007). In the current advanced era, knowledge and its applications are the most important element to organizations for success and competitive advantage.

According to Rasoulinezhad (2011), knowledge management is a discipline for identification, collection, organization, storage, sharing and application of knowledge. Knowledge management can also be viewed as an organizational strategic effort that is used to capture the knowledge of its employees and customers which are stored in database, document and employee's intellect to gain more benefit (Mohsen, 2011). It is concerned with developing and cultivating systems that enable organizations to detect, leverage, distribute and improve their knowledge assets.

Ethiopian banking history, in its modern sense, began towards the end of the reign of Emperor Menilek. This period witnessed the establishment of the country's first bank called the Bank of Abyssinia, or in Amharic "Ye-Ityopya Bank", an affiliate of the National Bank of Egypt, and was founded in 1905 (Micheal, 2011). Now a day, a number of private and government owned banking sectors are functional in all over the country. However, unlike the massive expansion of banking sector in the country, the nature of knowledge sharing practices in the banking sectors are not given due attention by domestic researchers. It is from this ground that, therefore, this research work is initiated to investigate the knowledge sharing practice of workers in the banking sector of Ethiopia. Specifically, this research focused on privately owned banking sector in Ethiopia i.e. Dashen Bank S.C of Ethiopia. 


\subsection{Statement of the Problem}

Wang and Noe (2010) noted that because of the potential benefits of knowledge management specifically knowledge sharing, many organizations have invested considerable amount of money into knowledge management initiatives and systems which use the latest technology to collect, store and share knowledge. However, most existing studies that are related to knowledge management is concerned with manufacturing industries, and, by contrast, the service industry, especially banking sector, has been given limited attention ( HRDI , 2001). The same contention holds true to the Ethiopian financial institutions as well. Hence, exploring the limitations and obstacles behind not implementing effective knowledge management system in the Ethiopian banking sectors was found to be a very timely and pressing issue.

According to Hayati and Nor (2006), from the total knowledge of an organization, $80 \%$ is evidenced to be in the mind of individuals and the remaining $20 \%$ is available in the form of explicit knowledge. Unless individuals interact and create mechanisms for converting and sharing these knowledge among themselves, their effort will only fetch a limited success in their organizations. Unquestionably, it needs good and sound ways to capture and share both the tacit and explicit knowledge of the employees. Having this fact in mind, conducting a research on tacit and explicit knowledge sharing and identifying barriers that could influence or hinder it becomes more justifiable.

Besides, knowledge sharing practice can be influenced by a number of different factors. Among the many factors, individual behaviors of employees, organizational cultures, existence of adequate IT infrastructures and employees communication are the major ones that have the power to influence knowledge sharing practices in the banking sectors (Al-Alawi et al., 2007). Hence, a detail investigation of those factors that determine the degree of practicing knowledge sharing in that specific organization seems vital. This study, as a result, shoulders the responsibility of investigating the prominent factors and their influence on the knowledge sharing practice of workers. The need to conduct this study is, therefore, very clear.

\subsection{Objectives of the Study}

\subsubsection{General Objectives}

The general objective of this study was to assess the knowledge sharing practices of employees working in Dashen Bank Share Company of Ethiopia.

\subsubsection{Specific Objectives}

The specific objectives of the research are to:

1. Assess whether there exist a difference in knowledge sharing practice among employees with regard to their age, sex, educational level, and work experience and employment status.

2. Examine the independent and combined contributions of workers' demographics (workers' age, sex, educational level, and work experience and employment status) on their knowledge sharing views.

3. Identify the prominent factors influencing knowledge sharing practice among employees of Dashen Bank S.C of Ethiopia.

4. Propose the best fitted model that is used to describe knowledge sharing practice among employees.

5. Identify the mode of knowledge sharing predominantly practiced in Dashen Bank S.C of Ethiopia.

\section{LITERATURE REVIEW}

\subsection{Data, Information, Knowledge and Wisdom Hierarchy}

Human beings, as intelligent beings, are in crave and search of knowledge for their day to day activities. This knowledge is attained by detecting, observing, perceiving and experiencing different phenomenon. The knowledge perceived must be recorded and represented for usage and possible communication with current and future generations (Liew, 2013). In today's world economy, tangible asset like land, labor and capital are no longer sufficient for countries development. Instead, using intangible asset of the organizations, i.e. knowledge, plays an important role. Knowledge has been lately recognized as one of the most important assets of organizations (Borghoff, 2007). According to Smith and Bollinger (2001), knowledge is the individual's ability to interpret information according to one's own experience, expertise and skills. Spender (1996) also noted that knowledge is a highly contentious concept and infinitely extensible which means that the use of knowledge by an individual does not restrict another to take advantage of it.

Concepts of data, information, knowledge, and wisdom are the building blocks of information science. The Data-Information-Knowledge-Wisdom hierarchy was first specified in detail by Ackoff in 1988 (Bernstein, 2009). Based on Ackoff's study, the content of human mind can be classified into five categories: data, information, knowledge, understanding and wisdom. The first four categories are related with past and deal with what has been or what is known. Only the fifth category deals with the future, because it incorporates vision and design (Bellinger et al., 2007). 


\subsection{Types of knowledge}

It is very important to understand that knowledge exist in different types, which needs diverse methods for creation and sharing in an organizations. In an organization, knowledge is often classified into different types. One possible classification of knowledge are tacit and explicit knowledge; individual, group and organizational knowledge; and shallow and deep knowledge. Furthermore, the other possible and widely used categorization of knowledge is as knowledge psychology, articulability and knowledge holder (Bornemann et al., 2003).

\subsection{Knowledge Management}

Knowledge management is based on the premise that human beings and organizations are unable to draw on the full potential of their brains and to fully utilize the knowledge that they possess. Through the application of knowledge management, organizations need to create actually useful knowledge and to make it available to those who can use it at a time and place that is appropriate for them to achieve maximum effective usage in order to positively influence organizational performance (King, 2009). Knowledge management is a process of applying a methodical approach to acquire, structure, and disseminate knowledge throughout the organization to work faster, reuse best practices, and reduce costly rework from task to task (Dalkir, 2005). Knowledge management, according to King (2009), is concerned with the utilization and development of the knowledge assets of an organization with the view of enhancing organizational objectives.

\subsection{Knowledge Management Process}

Knowledge constructing is an unstoppable process which has several elements including the idea generation (creation), grasping new models and mixing the theories/concepts for new processes (Jashapara, 2004). Inconsistency was observed in the literature with regard to the explanation of the knowledge management processes. The major approach in knowledge management cycle is proposed in Bukowitz and William's knowledge management cycle (2000), McElroy's knowledge management cycle (2003) and Wiig's knowledge management cycle (1993). Bukowitz and William's knowledge management cycle depicts the process that defines the strategy for management to build, divest, and enhance knowledge assets (Kayani and Qamar, 2012). This cycle divide knowledge management process into four cycle steps: Get, Contribute, Assess and Build and Sustain. In McElroy's knowledge management cycle, Knowledge life cycle consists of the processes of knowledge production and knowledge integration, with a series of feedback loops to organizational memory, beliefs, and claims and the business-processing environment.

\subsection{Importance of Knowledge Sharing in Organizations}

According to Gurteen (1999), the survival of almost all organizations is reliant on the creation and application of new knowledge and it is therefore inevitable that knowledge needs to be shared. In any organizations the implementation of knowledge management system gives emphasis for knowledge sharing behavior of the employees. Since the success of knowledge management initiatives largely depends on the willingness of organizational members to share their tacit knowledge (King, 2009). To create a knowledge sharing culture, it needs to encourage people to work together more effectively, to collaborate and to share in order to make organizational knowledge more productive.

\subsection{Barriers of Knowledge Sharing}

According to Hendriks (1999), knowledge sharing has been identified as a major area of emphasis for knowledge management. It provides a link between the level of the individual knowledge workers, where knowledge resides, and the level of the organization, where knowledge attains its economic and competitive value.

Barriers that influence knowledge sharing in public organizations classified into three categories, namely, individual factors, technological factors, and organizational factors. Individual barriers are factors related to the internal being of the individual, such as beliefs and perceptions. These could be linked directly or indirectly to external factors, such as the influence of national culture on the perceptions and beliefs of the individual. Organizational factors include the influence of the organizational culture, lack of proper integration between knowledge management activities and long term goals as well as objectives of the company, lack of proper leadership, and lack of appropriate rewards in the organization. Technological factors that hinder knowledge sharing are the unavailability of the required technological resources, including software and hardware to assist in implementation of knowledge management activities (Cheng et al., 2011).

\subsubsection{Nonaka's SECI model}

An organization creates knowledge through the interactions between explicit and tacit knowledge (Gourlay, 2004). The interaction between two types of knowledge is known as knowledge conversion. Through the conversion process, tacit and explicit knowledge expands in both quality and quantity. There are four modes of knowledge conversion. These are: (1) socialization (tacit knowledge to tacit knowledge); (2) Externalization (tacit knowledge to explicit knowledge); (3) Combination (explicit knowledge to explicit knowledge); and (4) 
Internalization (from explicit knowledge to tacit knowledge) (Gourlay, 2004). There is a spiral of knowledge involved in this model, where the explicit and tacit knowledge interact with each other in a continuous process. This process leads to creation of new knowledge. The central thought of this model is that knowledge held by individuals is shared with others so that it interconnects to a new knowledge.

Figure 1: Nonaka's modes of knowledge conversion

\section{Nonaka's Four Modes of Knowledge Conversion}

$\begin{array}{cccc} & \text { Tacit Knowledge } & \text { Tacit Knowledge } & \\ \begin{array}{c}\text { Tacit } \\ \text { Knowledge }\end{array} & \text { Socialization } & \text { Externalization } & \begin{array}{c}\text { Explicit } \\ \text { Knowledge }\end{array}\end{array}$

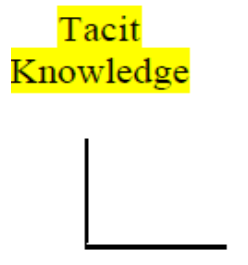

Internalization

Explicit Knowledge
Combination

\author{
Explicit
}

Knowledge

\subsubsection{Knowledge Assets}

Source: Nonaka and Takeuchi (1995)

Knowledge assets are the basis for knowledge creation process. Assets are firm's specific resources that are indispensable to create values and competitive advantage for the firm. Knowledge assets represent the fount of an organization's competences and capabilities that are deemed essential for its growth, competitive advantage and human development (Kamasak and Yucelen, 2010).

\subsection{Knowledge Management in Banking Sector}

Before 1960's, the banking sector had relied on manual skill and all customer account has been hand written. After the invention of mainframe computer, banking business highly becomes IT oriented (Kridan and Goulding, 2006).

In case of Ethiopia, as per knowledge of the researcher Habtamu (2011) conducted a study on the evaluation of knowledge sharing practice in commercial bank of Ethiopia. The aim of the research is to identify the barriers that hinder knowledge sharing practice among the employees of Commercial bank of Ethiopia (CBE) and to evaluate the extent of tacit knowledge sharing by group and individual in CBE.

In this regard, this study is intensively used primary data collection methods through questionnaire, interview and direct observation to gather information from the respondents. In addition, secondary data from publication annual reports, bulletins of CBE is consulted.

\section{METHODOLOGY OF THE STUDY}

\subsection{Research Design}

The quality of any research project is enhanced by employing a sound research design. Therefore, it is found to be important to choose appropriate research design to respond the research questions sufficiently. Accordingly, in this study, both qualitative and quantitative research approaches were dully considered. Thus, the current study makes use of a cross-sectional mixed methods research design. Specifically, concurrent mixed method research design was chosen in order to analyze and discuss the findings of the study. With concurrent mixed method research design, both quantitative and qualitative data was employed simultaneously for data analysis purpose, with one form of data playing a supportive role to the other (Creswell, 2008).

In brief, using the quantitative method, the researcher made an attempt to assess the degree of relationship between demographic variables and knowledge sharing practice. In particular, the degree of workers' knowledge sharing practice in terms of their age, sex, total years of work experience, educational level and employment status were examined using the quantitative research methods. With regard to the qualitative research design, the researcher had tried to uncover findings that gave better understanding of how knowledge sharing is practiced in DASHEN BANK S.C of Ethiopia. Specifically, the prominent factors influencing the occurrence of knowledge sharing practice in the bank, the respective reasons behind the existence of those debilitating factors are captured using a qualitative data obtained via the appropriate data collection instruments. 


\subsection{Participants of the Study}

The target populations of the study were workers extracted from Dashen Bank S.C of Ethiopia. Dashen Bank is chosen among other banks of the country because the researcher believed that it is a renowned private bank both with its age old service and the tremendous role it played to the economic development of the country.

Totally, about 175 subjects participated in the study, for collecting both the quantitative and qualitative information. Specifically, a total of 165 professional workers were chosen for filling the administered self-report questionnaire whereas the remaining 5 managers and 5 workers were chosen for conducting the semi-structured interview. For subjects recruited to the interview, purposeful sampling method was applied for which the researcher intentionally selects participants by considering their position and responsibility in the bank.

\subsection{Instruments and Procedures of Data Collection}

This study was based on both primary and secondary data sources. Mainly, self-administered questionnaires and semi-structured interviews were prepared and conducted to gather the relevant information.

\subsection{Techniques of Data Analysis}

The research involves both qualitative and quantitative data analysis techniques. Accordingly, both descriptive and inferential statistical analyses were employed appropriately for analyzing the quantitative data obtained. Regarding the qualitative analysis, the data obtained from semi-structured interview was narrated suitably in order to substantiate the information secured via the quantitative method. Thus, the degree of knowledge sharing practice, factors deemed to influence knowledge sharing practice in the banks, availability of IT infrastructures and the specific mode of the SECI model mostly applicable in the bank were well addressed through the qualitative approach, as a supportive to quantitative information obtained via the questionnaire instrument.

\section{RESULTS AND DISCUSSIONS}

The foremost purpose of this study was to assess the knowledge sharing practice of employees working in the banking sector. Specifically, assessing the existing knowledge sharing practice, identifying the barriers of knowledge sharing practice, appraising the availability of IT infrastructures and proposing a best fitted model were issues that this particular study is intended to embark upon. The study was conducted on employees in one of the privately owned bank, Dashen Bank S.C of Ethiopia.

\subsection{Demographic Characteristics}

Participants provided basic demographic information regarding their sex, age, educational level, years of experience, and employment status. The questionnaire was given to a total of 165 adult employees. However, only 142 of them completed and returned back. Out of these, nine questionnaires were removed from data analyses because of the invalid completion. The table below could explain the demographic characteristics of the research sample in detail.

As depicted in table 5 below, 89 (64.7\%) participants were emerging adults with age between 20 and 29 . Young adults comprised $39(29.3 \%)$ which aged between 30 and 39 whereas the remaining $8(6 \%)$ was comprised of the middle adults with age range between 40 and 49 . The lowest and the highest age level observed in the sample population were 21 and 49 respectively. None of the research participants were found to have over 49 years of age. Besides, the mean age level of the participants was about $28.4(\mathrm{SD}=5.5907)$. Regarding the sex of participants, males comprise $81(60.9 \%)$ of the total sample, while females make up the remaining $52(39.1 \%)$ of the total population of the study. 
Table 1: Summary of participant demographic data

\begin{tabular}{|c|c|c|c|c|c|c|c|}
\hline Characteristic & $\begin{array}{l}\text { Total Sample } \\
(\mathrm{N}=133)\end{array}$ & $\begin{array}{l}\text { Freque } \\
\text { ncy }(\%)\end{array}$ & Mean & SD & Variance & Min & $\operatorname{Max}$ \\
\hline Age & & & & & & & \\
\hline $\begin{array}{c}20-29 \quad \text { (emerging } \\
\text { adults) } \\
30-39 \text { (young adults) } \\
40-49 \text { (middle adults) }\end{array}$ & $\begin{array}{l}86 \\
39 \\
8 \\
\end{array}$ & $\begin{array}{c}64.7 \\
29.3 \\
6\end{array}$ & 28.398 & $\mathbf{5 . 5 9 0 7}$ & 31.257 & 21.00 & 49.00 \\
\hline$\overline{\operatorname{Sex}}$ & & & & & & & \\
\hline $\begin{array}{l}\text { Female } \\
\text { Male }\end{array}$ & $\begin{array}{l}52 \\
81\end{array}$ & $\begin{array}{l}39.1 \\
60.9\end{array}$ & 1.609 & .4898 & .240 & 1.00 & 2.00 \\
\hline $\begin{array}{l}\text { Total years of experience } \\
1-5 \text { (less experienced) } \\
6-10 \text { (experienced) } \\
\geq 11 \text { (highly experienced) }\end{array}$ & $\begin{array}{l}75 \\
40 \\
18\end{array}$ & $\begin{array}{l}56.4 \\
30.1 \\
13.5\end{array}$ & 1.5714 & .72075 & .519 & 1.00 & 3.00 \\
\hline $\begin{array}{r}\text { Educational Status } \\
\text { Diploma } \\
\text { Bachelor } \\
\text { Masters }\end{array}$ & $\begin{array}{l}23 \\
108 \\
2\end{array}$ & $\begin{array}{r}17.3 \\
81.2 \\
1.5\end{array}$ & 1.8421 & .40531 & .164 & 1.00 & 3.00 \\
\hline $\begin{array}{c}\text { Employment Status } \\
\text { Contract } \\
\text { Permanent }\end{array}$ & $\begin{array}{l}2 \\
131\end{array}$ & $\begin{array}{r}1.5 \\
98.5\end{array}$ & 1.9850 & .12216 & .015 & 1.00 & 2.00 \\
\hline
\end{tabular}

As far as the experience of research participants was considered, 75 (56.4\%) participants were found to be less experienced having a total working experience of below five years, which means more than half of the participants were found to be less experienced. The remaining 40 (30.1\%) and 18 ( $13.5 \%)$ of the participants were found to have average (between 6 and 10 years) and high working experience (with more than 11 years) respectively. With regard to educational status, the majority of the participants were found to be first degree holders 108 (81.2 \%). The lingering, $23(17.3 \%)$ of the participants were Diploma holders while only $2(1.5 \%)$ of the research participants were found to have a Masters degree. There was no employee recruited as a research sample having a $\mathrm{PhD}$ degree.

Regarding employment status, as indicated in the table above, 131 (98.5\%) of the study participants were working in Dashen Bank S.C of Ethiopia having a permanent work agreement whereas the minute remaining $1.5 \%$ of the respondents were working with a contract base agreement. Thus, because of the extreme skewed nature of this variable towards one side, the researcher has decided to exclude the variable "employment status" from considering it to further analysis.

\subsection{Group Differences in Knowledge Sharing Practice}

An exploratory analysis of the sample demographics was also conducted to detect whether there exists group differences among their scores of knowledge sharing practice. Particularly, a series of group mean analyses (Ttest, one way ANOVA and Post-hoc comparisons) were conducted to assess whether participant background and demographic characteristics accounted for differences in knowledge sharing practice of the participants of the study. As a result, participants' knowledge sharing practice is examined based on their sex, age, work experience and educational status.

Table 2: Differences in knowledge sharing practice in terms of participants' Age

\begin{tabular}{|c|c|c|c|c|c|c|c|c|}
\hline \multirow[b]{2}{*}{ Groups } & \multirow[b]{2}{*}{$N$} & \multirow[b]{2}{*}{ Mean } & \multirow[b]{2}{*}{$S D$} & \multirow[b]{2}{*}{$F$} & \multirow[b]{2}{*}{ Sig } & \multicolumn{3}{|c|}{ Post Hoc Tests } \\
\hline & & & & & & Groups & $M D$ & Sig. \\
\hline Emerging adults & 86 & 3.1252 & .3114 & & & $\mathrm{E}$ and $\mathrm{Y}$ & -.0239 & .939 \\
\hline Young adults & 39 & 3.1491 & .3842 & $5.387^{* *}$ & .006 & $E$ and $M$ & $.4093^{* *}$ & .008 \\
\hline Middle adults & 8 & 2.7158 & .5464 & & & $\mathrm{Y}$ and $\mathrm{M}$ & $.4332^{* *}$ & .008 \\
\hline
\end{tabular}

**Significant at the 0.01 level (2-tailed).

*Significant at the 0.05 level (2-tailed).

As indicated in table 6, a test of differences in mean scores of knowledge sharing practice in terms of participants' age revealed that there was a statistically significant difference among the emerging, young and middle adult employees $(\mathrm{F}=5.387, \mathrm{p}=.006)$. An inspection of the mean scores showed that young adults reported slightly better levels of knowledge sharing practice $(\mathrm{M}=3.1491, \mathrm{SD}=.3842)$ than the emerging $(\mathrm{M}=$ $3.1252, \mathrm{SD}=.3114)$ and middle adults $(\mathrm{M}=2.7158, \mathrm{SD}=.5464)$. Comparatively speaking, the middle adults 
(age between 40 and 49) were found have an endangered mean scores of knowledge sharing views than the young and emerging adults.

When significant differences among the groups is observed, just like this particular result, additional analysis was needed to locate the source of the difference. To this end, a Post-hoc test using Scheffe method was performed (see table 6 to the details of the post-hoc result). Accordingly, a statistically significant difference in knowledge sharing practice was observed between emerging (age between 20 and 29) and middle (age between 40 and 49) adults $(\mathrm{MD}=.4093, \mathrm{p}=.008)$. Similarly, the difference in knowledge sharing practice between young (age between 30 and 39) and middle adults was also found to be statistically significant (MD $=.4332, p$ $=.008)$. However, the difference in knowledge sharing practice scores between those who are emerging and young was not significant $(\mathrm{MD}=-.0239, \mathrm{p}=.939)$.

Some consistent and contrasting results were also established in research works conducted in different settings and sample characteristics. For instance, this result was found to be consistent with the findings of Lin (2006). According to Lin (2006), young individuals who have grown up in the high technology era are more likely to better understand the importance of knowledge sharing and in turn utilize IT infrastructures essential to share knowledge and information than the older ones. In this particular finding, younger adults were found in a better position of building positive attitude towards sharing information and knowledge than both the emerging and older adult workers.

The emerging ones showed a lesser practice towards knowledge sharing than the young adults because of two possible reasons. On one hand, the emerging adults, as compared to the younger and older ones, are uncertain about the value of the knowledge they possessed (Riege, 2005) and hence lack confidence in sharing knowledge and ideas among their colleagues. On the other hand, because these individuals are new comers to the institution in which they are working, it became difficult to them to build good friendship relations with the staff, which is fundamental in forming grounds for sharing knowledge and ideas among the staff members.

However, contrasting results were also established by a couple of research findings conducted to identify whether there exist a difference in knowledge sharing practices regarding individuals' age. Accordingly, research works by Pangil and Nasurdin (2008) and Ismail and Yusof (2009) revealed that there is no significant difference in knowledge sharing practices with regard to the age of participants. One justification raised to the non-significant difference observed among participants of different age groups was that knowledge and information sharing activities is an important aspect of their day to day activities, regardless of their chronological age (Pangil and Nasurdin, 2008). This is to mean that for individuals who are working in institutions like the banking sector, knowledge sharing is part of their jobs irrespective of their age differences.

Table 1: Differences in knowledge sharing practice in terms of participants' Sex

\begin{tabular}{lcccccc}
\multicolumn{1}{c}{ Groups } & N & Mean & SD & t & df & Sig \\
\hline Female & 52 & 3.1905 & .3491 & \multirow{2}{*}{$2.147^{*}$} & \multirow{2}{*}{131} & .034 \\
Male & 81 & 3.0544 & .3616 & & & \\
\hline
\end{tabular}

**Significant at the 0.01 level (2-tailed).

*Significant at the 0.05 level (2-tailed).

In order to examine the differences in knowledge sharing practice across sex, an independent t-test was computed. With this method, examining the difference in mean score of a variable among groups of two categories is possible. As seen in table 7 above, a statistically significant difference was observed between male and female employees of Dashen Bank S.C in their knowledge sharing practice $(\mathrm{t}=2.147, \mathrm{p}=.034)$. Thus, female employees exhibited a significant higher mean score of knowledge sharing practice $(\mathrm{M}=3.1905, \mathrm{SD}$ $=.3491)$ than their male counterparts $(\mathrm{M}=3.0544, \mathrm{SD}=.3616)$.

Knowledge sharing practice is found to be more positive among female workers most probably because females are keener to build a good relationship and interaction among their colleagues in the work place than male workers. Hence, during their time of social interactions, female could get a better opportunity of discussing more about their organization in general and their departmental work activities in particular. Therefore, from this knowledge and information sharing behavior that female workers are accustomed to, it is possible to say that they could build a positive attitude towards sharing knowledge among the staff members than the male workers.

Previous studies also document similar findings regarding the difference in knowledge sharing practices comparing male and female workers. For instance, Lin (2006) found that women are more willing to share knowledge because they are more sensitive to instrumental ties and due to the need to overcome traditional occupational hurdles. This is to mean that females consider sharing knowledge as vital instrument to their development in their career structure than their male counterparts do. Lin (2006) further point out that female workers gained more benefits from knowledge sharing than the males. This finding indicated that there is a possibility that women might want to share more knowledge as compared to men because they want to be perceived as more knowledgeable and providing them more opportunity to further their career. 
However, a study by Miller and Karakowsky (2005), who looked into the difference in knowledge sharing behavior among male and female workers, revealed that the difference between women and men is visible in favor of the later one. As to them, male workers are relatively advanced in their effort to seek for knowledge than females are. Moreover, similar to the research findings of Miller and Karakowsky (2005), Hareya (2011) also believed that views of knowledge sharing is much better understood and communicated among male employees of an organization. This finding was also replicated by Pangil and Nasurdin (2008). Besides, a different result was also obtained by Ismail and Yusof (2009). According to these researchers, there is no significant difference in knowledge sharing views between male and female workers.

A test of difference in mean scores of knowledge sharing views in terms of participants' work experience was also examined. The result, as indicated in table 8 , revealed that there is a significant difference in knowledge sharing views regarding respondents work experience $(\mathrm{F}=3.132, \mathrm{P}=.047)$.

Table 3: Differences in knowledge sharing practice in terms of work experience

\begin{tabular}{lcccccccc}
\hline \multicolumn{1}{c}{ Groups } & N & Mean & SD & F & Sig & Groups & MD & Sig. \\
\hline Less experienced & 75 & 3.1460 & .31732 & & & L and E & .0233 & .946 \\
Experienced & 40 & 3.1227 & .32324 & $3.132^{*}$ & .047 & L and H & $.2319^{*}$ & .049 \\
Highly experienced & 18 & 2.9141 & .53960 & & & E and H & .2085 & .123 \\
\hline
\end{tabular}

**Significant at the 0.01 level (2-tailed).

*Significant at the 0.05 level (2-tailed).

A critical observation of the mean scores of the three groups also could tell us something fundamental. Accordingly, adults with lower level of work experience were found to have a relatively better knowledge sharing practice $(\mathrm{M}=3.1460, \mathrm{SD}=.3173)$ than those with average levels of experience $(\mathrm{M}=3.1227, \mathrm{SD}$ $=.3232)$ and higher level of work experience $(\mathrm{M}=2.9141, \mathrm{SD}=.5396)$. Thus, employees with higher work experience ( $>11$ years) were found to have lower level of attitude towards sharing knowledge with others than employees with less ( $<5$ years) and average (between 5 and 10 years) years of working experience.

Further analysis was also made using a post hoc comparison in order to identify the pair-wise differences existed among the three categories of work experience. Accordingly, the only significant difference in mean scores of knowledge sharing practice was observed between those employees having lower and higher years of work experience $(\mathrm{MD}=.2319, \mathrm{p}=.049)$. Otherwise, the difference between employees with lower and average work experience $(\mathrm{MD}=.0233, \mathrm{p}=.946)$ and between average and high work experience was not significant $(\mathrm{MD}=.2085, \mathrm{p}=.123)$.

The difference in knowledge sharing practice between the less experienced and highly experienced workers could be possibly explained that the less experienced are more prone to using IT infrastructures and internet systems for communicating purposes than the later ones. The less experienced workers are closer to make use of social medias (like facebook, twitter, Skype, youtube, diretube, etc.) and other information gaining mechanisms of the internet (such as e-mail, Google, etc.), which are basic for exchanging knowledge and information, than the more experienced workers. This in turn would boost the view of less experienced workers towards knowledge sharing with the staff members of the organization.

However, preceding research findings on the issue documented that highly experienced workers are better in building a better view of sharing knowledge than the less experience ones. For instance, Collin (2004) tried to attach one's experience with position and power and relate with knowledge sharing behavior. According to him, the longer the person is serving in an institution and having a certain position in that specific institution, the more comfortable he or she is with the knowledge that he/she possess in relation to that job, and therefore the more he or she is able to share the knowledge with others. He further explains the situation by stressing on its relationship with mentoring and monitoring behaviors. For Collin (2004), senior employees often acted as a monitor to less experienced employees. In monitoring and mentoring relationship, where knowledge sharing often occurs, the monitors and mentors are often employees with higher experience. Thus highly experienced workers would in turn develop a better view of and operate knowledge sharing practices appropriately than the less experienced ones.

The final examination of group mean differences in employs level of knowledge sharing practice was conducted on educational status. As vividly detailed in table 9 below, another statistical significant difference was observed in the mean scores of knowledge sharing practice among different groups of educational status ( $\mathrm{F}$ $=4.107, \mathrm{p}=.019)$. Thus, it seems that educational status is an imperative variable that influences the extent of knowledge sharing among employees of organizations like DASHEN BANK S.C. The mean scores of the groups also witnessed that, the better the education status the healthier the knowledge sharing practice is. Accordingly, Master holders reported a relatively better level of knowledge sharing views $(\mathrm{M}=3.7726$, SD $=.0642)$ than the bachelor holders $(\mathrm{M}=3.1119, \mathrm{SD}=.3488)$; the bachelor holders in turn were found to report a better level of knowledge sharing practice than their diploma holder counterparts $(\mathrm{M}=3.0296, \mathrm{SD}=.3826)$. 
With regard to the pair-wise differences seen among the three groups of educational status, a significant difference was observed between employees of diploma and master holders (MD = -.7430, $p=.019$ ) as well as between bachelor and master holders $(\mathrm{MD}=-.6607, \mathrm{p}=.035)$. However, a statistically significant difference was not observed among employs having a diploma and bachelor degree (MD = -.0823, $\mathrm{p}=.599)$. In short, the result revealed that as one boosts his profile of educational status, the more likely he would also be in building a better perception and practice of sharing knowledge with others.

Table 2: Differences in knowledge sharing practice in terms of Educational Status

\begin{tabular}{lrrrrrrrr}
\hline \multicolumn{1}{c}{ Groups } & & & & & & \multicolumn{3}{c}{ Post Hoc Tests } \\
\cline { 7 - 9 } & $\boldsymbol{N}$ & Mean & SD & $\boldsymbol{F}$ & Sig & Groups & MD & Sig. \\
\hline Diploma holders & 23 & 3.0296 & .38266 & & & D and B & -.0823 & .599 \\
Bachelor holders & 108 & 3.1119 & .34880 & $4.107^{*}$ & .019 & D and M & $-.7430^{*}$ & .019 \\
Master holders & 2 & 3.7726 & .06427 & & & B and M & $-.6607^{*}$ & .035 \\
\hline
\end{tabular}

**Significant at the 0.01 level (2-tailed).

*Significant at the 0.05 level (2-tailed).

Note: $S D=$ Standard Deviation; $M D=$ Mean Difference

The significant difference in knowledge sharing practice and the increasing trend from lower to higher educational level is to imply that the more the educational level of the workers the better their attitude towards knowledge sharing practice be. The finding is perhaps from the ground that higher education level lends a hand to be well informed and accumulate a better knowledge, especially in the field of their work. Building better knowledge in turn would enhance one's confidence in the knowledge he/she possesses and subsequently will be motivated to create environments for knowledge sharing among the staff members. The associated feedbacks and recognitions would then inevitably boost their knowledge sharing practice. Thus, workers with higher educational level have a better chance of forming a better knowledge sharing practice than those workers with lower educational level forms.

This particular result was also consistent with the research findings of Tan et al. (2010). According to Tan and his colleagues (2010), the well-educated individuals are employees who have better understanding and practice of knowledge sharing than the less educated ones. However, contrasting to mine and Tan's result, the findings of Pangil and Nasurdin (2008) revealed that employees with bachelor's degree holders, who are less educated as compared to master's degree holders, were found to build a better understanding of knowledge sharing. However, to this result, the possible explanation put forward was that the master holders were those who are aged and hence the aged could fetch lower levels of knowledge sharing practice than the younger ones. Thus, in this case, participants' age is acting as a moderator variable to come amid the relations between educational level and knowledge sharing practice.

\subsection{Relations among Demographics and Knowledge Sharing Practices}

Subsequent multiple correlations were also run to examine relationships among the variables of the study. The bivariate Pearson product-moment correlation was employed to describe the strength and direction of the linear relationships among the variables. Hence, bivariate correlations were computed for demographic variables (sex, age, work experience, and educational status) and knowledge sharing practice. The size of the value of Pearson correlation was interpreted using Cohen's (1988, in Creswell, 2008) guideline: $r=.10$ to .29 as small; $r=.30$ to .49 as medium; and $r=.50$ to 1.0 as large. The relationships among the study's variables are presented in Table 10 below. Only significant correlations relevant to the current study's research questions and potential implications of these correlations are presented.

Table 3: Means, Standard deviations and Intercorrelations among variables of the study

\begin{tabular}{|c|c|c|c|c|c|c|c|}
\hline Variables & Mean & SD & 1 & 2 & 3 & 4 & 5 \\
\hline 1. Sex & 1.6090 & .4898 & - & & & & \\
\hline 2. Age & 28.398 & 5.5907 & -.045 & - & & & \\
\hline 3. Educational Status & 1.8421 & .4053 & .106 & $.242^{* *}$ & - & & \\
\hline 4. Work Experience & 1.5714 & .7207 & $-.221^{*}$ & $.751^{* *}$ & $.207^{*}$ & - & \\
\hline 5. Knowledge Sharing practice & 3.1076 & .36171 & $-.184^{*}$ & $-.227^{* *}$ & .161 & $-.185^{*}$ & - \\
\hline
\end{tabular}

**. Correlation is significant at the 0.01 level (2-tailed).

*. Correlation is significant at the 0.05 level (2-tailed).

The above table presents the correlations between demographics and knowledge sharing practice of the research participants. Accordingly, the demographic variable of sex was negatively and significantly correlated with work experience $(r=-.221, \mathrm{p}<.05)$ and knowledge sharing practice $(\mathrm{r}=-.184, \mathrm{p}<.05)$. The result suggests that female participants had a higher level of work experience as compare to their male counterparts. Moreover, the significant negative relationship between sex and knowledge sharing practice implies that females are in a 
better position of sharing their knowledge with others than the male employees do.

Similarly, a significant negative association was also observed between participants' age and their knowledge sharing practice $(\mathrm{r}=-.227, \mathrm{p}<.01)$. That means, the more adults are towering in their age, the less they would likely be to share their knowledge to others and sharing others' knowledge to themselves as well. To say it the other way, being younger is beneficial in building better attitude of sharing knowledge than being older. Age was, however, positively and significantly correlated with participants' educational status $(r=.242, p<.01)$ and work experience $(\mathrm{r}=.751, \mathrm{p}<.01)$, suggesting that those employees with advanced chronological age are also those with better educational status and higher level of work experience.

Regarding educational status, participants' educational status was found to form a significant positive correlation with work experience $(\mathrm{r}=.207, \mathrm{p}<.05)$. The result suggests that adults with higher levels of work experience are also those having a better opportunity of being labeled in a better educational status. However, the relationship between participants' educational status and their knowledge sharing practice was not significant, though the correlation coefficient was positive $(r=.161)$, in favor of to those who have a higher levels of educational status.

Finally, work experience was found to have a significant association with all the remaining variables treated in the correlational analysis. Specifically, respondents' work experience formed a significant correlation with age $(\mathrm{r}=.751, \mathrm{p}<.01)$ and educational status $(\mathrm{r}=.207, \mathrm{p}<.05)$, whereas its relationship with $\operatorname{sex}(\mathrm{r}=-.221, \mathrm{p}<.05)$ and knowledge sharing practice $(r=-.185, \mathrm{p}<.05)$ was negative and significant. The strong correlation result revealed the common fact that age and experience are directly related to each other. Besides, the relationship between work experience and knowledge sharing practice was negative and significant, implying that the more the work experience, the less their attitude would be towards sharing knowledge to others and to themselves. In other words, those employees who have accumulated higher years of work experience are those with endangered extent of knowledge sharing views among their staff members.

In addition to the correlation analysis, the associations existed between variables was also tested using regression analysis. Consequently, a simultaneous multiple regressions is run to examine which of the predictor variables significantly accounted for variance in the criterion variables of the study. The major predictor variables included demographics; such as sex, age, work experience and educational status. The criterion variable of the study is knowledge sharing practice. In the regression analysis, the amount of variance each predictor accounts for in the outcome variable was determined. With the assumption of examining the unique variance explained by each predictor variable within the regression model, part correlation (part r) was also examined and presented along with the regression model. In brief, column and raw headings in the regression tables include the multiple correlation $(R)$, the coefficient of determination $\left(R^{2}\right)$, the $F$ value for the variable entered $(F)$, the standardized beta coefficient $(\beta)$, the uniquely variance explained (part $r$ ) and the level of statistical significance (p). Accordingly, only variables with significant independent contributions are explained, next to table 11 below.

Table 4: Regression analyses examining the contributions of demographic variables

\begin{tabular}{|c|c|c|c|c|c|c|}
\hline & \multicolumn{6}{|c|}{ Knowledge sharing practice } \\
\hline & $\bar{\beta}$ & sig & Part $\mathbf{r}$ & $\mathbf{R}$ & $\mathbf{R}^{2}$ & $\mathbf{F}$ \\
\hline Sex & $-.256 * *$ & .003 & -.243 & & & \\
\hline Age & -.184 & .146 & -.118 & 401 & 161 & $6146 * *$ \\
\hline Work Experience & $.266 * *$ & .002 & .255 & .401 & .101 & 0.140 \\
\hline Educational Status & -.159 & .219 & -.100 & & & \\
\hline
\end{tabular}

**significant at $\mathrm{P}<.01$

*significant at $\mathrm{P}<.05$

Table 11 shows the inclusion of demographic variables in predicting respondents' knowledge sharing practice. As evidenced by the ANOVA result of the regression analysis, the regression model, including demographic variables as predictors and knowledge sharing practice as outcome variable, was found to exhibit a significant variance $\left(\mathrm{F}=6.146, \mathrm{p}<.01, \mathrm{R}^{2}=.161\right)$. This is to mean that the predictor variables could bring a significant variance in the mean score of knowledge sharing practice of the respondents. Thus, the model encompassing sex, age, educational status and work experience together explained about $16.1 \%$ of the total variance in knowledge sharing practice. The remaining $83.9 \%$ of the variance in knowledge sharing practice is accounted by variables other than these.

Specifically, respondents' knowledge sharing practice was significantly predicted by sex $(\beta=-.256, \mathrm{p}<.01$, part $\mathrm{r}=-.243)$ and work experience $(\beta=.266, \mathrm{p}<.01$, part $\mathrm{r}=.255)$. Thus, as indicated by the part correlation result of the respective regression analysis, about $5.9 \%$ and $6.5 \%$ of the unique variance in employees' knowledge sharing practice was explained by sex and work experience respectively. Thus, these two variables jointly explain about $12.4 \%$ of the unique variance in knowledge sharing practice. Or, this much percent of the variance in knowledge sharing practice is accounted by the predictor variables of sex and work experience alone. 
On the other hand, the result revealed that participants' knowledge sharing practice was not significantly predicted by their age and educational status.

\subsection{Factors Influencing Knowledge Sharing Practice}

In order to respond to the second major research question that seeks to know the prominent factors meant to influence knowledge sharing practice in the organization, the researcher had developed a questionnaire with Likert type scale. For the sake of simplicity and manageability of analysis, relying on dependable literature reviews, the researcher designed the scale by organizing the factors in to fourteen major categories. Accordingly, the major factors explained by the items of the scales were reward and recognition, lack of time, lack of motivation, IT infrastructure, formal/ informal activities, organizational culture, lack of interaction among organizational members, absence of retention, physical work environment, trust, fear of misunderstood, lack of confidence, selfishness and communication skill. Thus, the respondents' response based on their responses of the degree of the influence of these factors is presented using frequencies and percentages. For easy comprehension, the frequencies and percentages of the scale measures "strongly disagree" and "disagree" as well as "agree" and "strongly agree" are summed together to denote the "no" and "yes" of the presence of the factors in influencing the existence of knowledge sharing practice in Dashen Bank

Moreover, with the aim of supplementing and triangulating the data generated through the above instrument, the researcher also conducted a semi-structured interview about the influential factors with five branch bank managers and five ordinary worker of the bank. The data obtained via the interview is analyzed by intermingled it with the questionnaire results. While analyzing the interview data, codes like "IM" and "IW" were used to represent the information from "interview with manager" and "interview with worker" respectively. Likewise, IM2 and IW4 denote "interview with the second manager" and "interview with the fourth worker." Hence, results obtained about the factors that influence the practice of knowledge sharing in Dashen Bank S.C is presented and discussed as follows.

As clearly depicted in table 12 above, a total of fourteen factors were listed to the respondents to rate the degree of their influence in influencing the availability of knowledge sharing practice in Dashen Bank S.C of Ethiopia. Accordingly, seven of the factors were rated as having a big influence to the practice whereas the remaining seven were rated as having lower degree of influence in influencing the practice of sharing knowledge in the bank. Specifically, $74.4 \%$ of the respondents believed that the existence of rewards and recognition as a major factor in determining the extent of knowledge sharing among employees. Thus, the lack of rewards and recognition systems that would motivate people to share their knowledge was a major factor that detracts employees of Dashen Bank S.C from sharing their knowledge to a sound degree. However, none of the interview data fetch lack of rewards and recognition as a factor influencing the degree of knowledge sharing practices in the organization.

A massive amount of respondents, i.e. $81.9 \%$, have also reported that the availability of information technology infrastructure was the promising factor in influencing the culture of knowledge sharing among employees of Dashen Bank S.C of Ethiopia. Hence, shortage of IT infrastructure and IT systems could enhance the habit of knowledge sharing are factors that endanger the prevalence of better knowledge sharing practice in the organization. This was also a factor backed by all of the interview respondents from the workers group. Specially, IW1, IW2 and IW5 contend that the prohibition of accessing social medias and private communication mechanisms in the organization prohibit workers from not only updating themselves but also sharing information with each other. According to them, accessing these mechanisms of information communication is not allowed in the office even if they are in part time. 
Table 5: Prominent factors affecting knowledge sharing practice in Dashen Bank

\begin{tabular}{|c|c|c|c|c|c|c|c|c|c|c|c|}
\hline \multirow{3}{*}{ No. } & \multirow{3}{*}{ Factor Categories } & \multirow{3}{*}{ Mean } & \multirow{3}{*}{ SD } & \multicolumn{8}{|c|}{ Response Alternatives } \\
\hline & & & & \multicolumn{2}{|c|}{$\begin{array}{l}\text { Strongly } \\
\text { Disagree } \\
\end{array}$} & \multicolumn{2}{|c|}{ Disagree } & \multicolumn{2}{|c|}{ Agree } & \multicolumn{2}{|c|}{$\begin{array}{c}\text { Strongly } \\
\text { Agree }\end{array}$} \\
\hline & & & & Freq. & $\%$ & Freq. & $\%$ & Freq. & $\%$ & Freq. & $\%$ \\
\hline 1 & $\begin{array}{l}\text { Reward and } \\
\text { Recognition }\end{array}$ & 2.909 & .8299 & 9 & 6.8 & 25 & 18.8 & 68 & 51.1 & 31 & 23.3 \\
\hline 2 & Time & 2.414 & .8268 & 18 & 13.5 & 53 & 39.8 & 51 & 38.3 & 11 & 8.3 \\
\hline 3 & Lack of Motivation & 2.301 & .8347 & 22 & 16.5 & 59 & 44.4 & 42 & 31.6 & 10 & 7.5 \\
\hline 4 & IT Infrastructure & 3.150 & .8024 & 5 & 3.8 & 19 & 14.3 & 60 & 45.1 & 49 & 36.8 \\
\hline 5 & $\begin{array}{l}\text { Formal/ Informal } \\
\text { Activities }\end{array}$ & 2.714 & .8031 & 10 & 7.5 & 37 & 27.8 & 67 & 50.4 & 19 & 14.3 \\
\hline 6 & $\begin{array}{l}\text { Organizational } \\
\text { Culture }\end{array}$ & 2.684 & .9404 & 16 & 12.0 & 38 & 28.6 & 51 & 38.3 & 28 & 21.1 \\
\hline 7 & Lack of Interaction & 2.639 & .7720 & 10 & 7.5 & 42 & 31.6 & 67 & 50.4 & 14 & 10.5 \\
\hline 8 & Absence of Retention & 2.677 & .9007 & 14 & 10.5 & 40 & 30.1 & 54 & 40.6 & 25 & 18.8 \\
\hline 9 & $\begin{array}{l}\text { Physical work } \\
\text { environment }\end{array}$ & 2.455 & .8426 & 19 & 14.3 & 45 & 33.8 & 58 & 43.6 & 11 & 8.3 \\
\hline 10 & Trust & 1.974 & .8579 & 45 & 33.8 & 52 & 39.1 & 30 & 22.6 & 6 & 4.5 \\
\hline 11 & $\begin{array}{l}\text { Fear } \\
\text { misunderstood }\end{array}$ & 2.158 & .8947 & 33 & 24.8 & 57 & 42.9 & 32 & 24.1 & 11 & 8.3 \\
\hline 12 & Lack of confidence & 1.909 & .8743 & 49 & 36.8 & 55 & 41.4 & 21 & 15.8 & 8 & 6.0 \\
\hline 13 & Selfishness & 2.011 & .8449 & 38 & 28.6 & 64 & 48.1 & 22 & 16.5 & 9 & 6.8 \\
\hline 14 & Communication skill & 2.342 & .9482 & 29 & 21.8 & 45 & 33.8 & 43 & 32.3 & 16 & 12.0 \\
\hline
\end{tabular}

Besides, $64.7 \%$ of the respondents also agreed that their knowledge sharing practice is strongly influenced by the lack of formal and informal activities. Formal and informal activities like meetings, trainings, workshops, orientations, kick off programs, get-together etc are therefore major factors that hinder workers from sharing their knowledge and experiences to each other. This point is also pointed out by interview respondents from the manager as well as the workers group. Thus, IM2, IM3 from the managerial group and IW1, IW2, IW4 and IW5 from the workers group contend that lack of sufficient amount of informal and formal activities that could enhance the culture of knowledge sharing practices are foremost factors to be mentioned in the lesser extent of knowledge sharing environment in the bank.

The fourth factor deemed to sway the culture of knowledge sharing in Dashen Bank S.C of Ethiopia was organizational culture. A total of $59.4 \%$ of the respondents rated this factor as influential in dwindling knowledge sharing practice. That means, the previous and long lived culture of the organization itself didn't encourage the interaction and in turn the exchange of information and knowledge among the employees. Hence, unless the employees could enjoy an organizational culture that sufficiently supports interactions and knowledge sharing, employees would found it difficult to challenge the prevailing culture and in turn share ideas, information and knowledge among themselves. IW2 also asserted that the sole organizational culture prevailed in the bank is "to work" from the beginning to the end of working hours of the day, than treating and facilitating other agendas related to entertainment or knowledge sharing conditions.

Lack of interaction was the fifth factor rated by the respondents to have a strong influence in affecting the degree of knowledge sharing in the organization. As indicated in the table above, about $60.9 \%$ of the respondents reply that lack of interaction between those who need and those who could provide knowledge and information was a key factor in diminishing the extent of knowledge sharing practice. IM1, IM4 and IM5 of the managerial group assert that workers' lack of interest to interact and discuss on social issues and scientific knowledge are major factors affecting the knowledge sharing practices of the organization. However, according to IW2 and IW5 of the working group, the nature of the work, time constraint and the staff sitting arrangement plays a major role in protecting workers to interact and discuss on issues together.

Absence of retention of highly skilled and knowledge workers was also another factor that could affect the development of knowledge sharing practices. A total of about $59.4 \%$ of the respondents were in favor of this factor in its influence in declining the knowledge sharing practices of the organization. This factor was also noted by interviewee respondents. Consequently, IW1 and IW2 contend that the subsequent release of experienced and knowledgeable workers from the organization and replacement of freshman and less experienced workers in turn is major factor that hinder employees to gain sufficient information and knowledge about the nature of the work at large.

Finally, the seventh factor slightly rated by the respondents to influence knowledge sharing practice was the physical work environment of working offices. Accordingly, about $51.9 \%$ of the respondents argue that the 
physical work environment and layout of work offices have played a great role in restricting the existence of effective knowledge sharing practices in Dashen Bank S.C of Ethiopia. IW5, specifically, criticizes the sitting arrangements and location of the places as a discouraging element of exchanging ideas and sharing information.

Nevertheless, there are also factors mentioned by the interviewee that strongly influence the development of knowledge sharing practices in the organization other than the above factors. For instance, except IM4, all the interview respondents of the managerial group believed that low "motivation" of the workers as a foremost factor to be mentioned to influence knowledge sharing practices in the bank. The interview respondents from workers group, such as IW2 and IW3, also stated that lack of motivation as good factor influencing the knowledge sharing practices prevailed in their respective organization.

On the other hand, IM3 and IM4 of the managerial group and IW1, IW2, IW4 and IW5 of the worker group emphasized on the "lack of time" to share knowledge and discuss with ideas as an influential factor. Similarly, IM1 believed that employees might not share their knowledge because of the poor interpersonal and communication skill they have. IM5 and IM2 of the managerial group also assert that "self confidence" as a key factor in affecting knowledge sharing practices. According to them, the low competence belief of the employees in the knowledge they have is the major factor that hinder them from cultivating the culture of knowledge sharing.

In sum, lack of rewards and recognition systems, lack of time to share knowledge, low motivation of sharing knowledge, scarcity and prohibition of using IT infrastructures, lack of formal and informal awareness creating activities, lack of interaction among the staff members, poor physical work environment and office layouts, and poor interpersonal and communication skills among the employees were prominent factors identified in influencing the development of the culture of knowledge sharing practices in Dashen Bank S.C of Ethiopia. Especially, the shortage of IT infrastructures and communications systems was a factor most noted both in the questionnaire as well as the interview respondents. To this end, the researcher tries to go through the issue by developing a questionnaire aiming to dig the availability of these IT infrastructures in the organization. To this end, the upcoming section will devote itself to detail results regarding the availability of IT infrastructures in Dashen Bank S.C of Ethiopia.

\subsection{Availability of Information Technology Infrastructures in DASHEN BANK}

As noted in the above section, the foremost factor mentioned to influence knowledge sharing practice in Dashen Bank S.C of Ethiopia was the scarcity of information technology infrastructure. Grounded from the fact that the availability of IT infrastructures is vital to the development of the culture of knowledge sharing practices in an organization, the researcher tries to go a step forward to identify the presence of IT infrastructures in Dashen Bank. To this end, a questionnaire encompassing 9 items, aimed to dig information regarding the existence and utilization of different IT infrastructure in the bank, with Likert type of scale measure was developed and the desired information was collected. The methodology followed in analyzing the data generated through this instrument is similar to the previous one. Accordingly, the cumulative percentages of allied paired alternatives are used to determine the existence and utilization of IT infrastructures vital to enhance knowledge sharing practices in the organization. Moreover, the data secured through the interview conducted with the bank managers and workers is also used as a means of triangulating and assisting the information gathered through the self-administered questionnaire instrument. Similar to the previous section, the coding scheme employed to denote the managers and workers is as "IM" and "IW" respectively.

As far as the presence of IT systems and processes is considered, as shown in table 13 above, about $60.2 \%$ of the respondents believed that there is scarcity of IT systems and processes fundamental to cultivate the culture of knowledge sharing among the employees of the organization. Only $39.8 \%$ of the respondents supposed that sufficient amount of IT systems and processes are in place in the organization to share knowledge. Likewise, IW2 and IW5 emphasized on the shortage of IT systems and processes in the organization where as IM3 argues that adequate amount of IT systems and processes are in place in the organization to satisfy employees need to share their knowledge among themselves. Similar to this question was the question raised under item 5 . It requests respondents to forward their idea regarding the ease of use of user-friendly IT systems in the organization for sharing their knowledge. As indicated above in table $13,70.6 \%$ of the respondents were against the presence of user-friendly IT systems in the organizations. Correspondingly, IW2 and IW5 were also against the presence of such IT systems vital to share information and knowledge. 
Table 6: Availability of Information Technology Infrastructure in Dashen Bank .

\begin{tabular}{|c|c|c|c|c|c|c|c|c|c|c|c|}
\hline \multirow[b]{3}{*}{ No. } & \multirow{3}{*}{ Items } & \multirow{3}{*}{ Mean } & \multirow{3}{*}{ SD } & \multicolumn{8}{|c|}{ Response Alternatives } \\
\hline & & & & \multicolumn{2}{|c|}{$\begin{array}{l}\text { Strongly } \\
\text { Disagree }\end{array}$} & \multicolumn{2}{|c|}{ Disagree } & \multicolumn{2}{|c|}{ Agree } & \multicolumn{2}{|c|}{$\begin{array}{c}\text { Strongly } \\
\text { Agree }\end{array}$} \\
\hline & & & & Freq. & $\%$ & Freq. & $\%$ & Freq. & $\%$ & Freq. & $\%$ \\
\hline 1 & $\begin{array}{l}\text { IT systems and processes are } \\
\text { in place. }\end{array}$ & 2.233 & .999 & 38 & 28.6 & 42 & 31.6 & 37 & 27.8 & 16 & 12.0 \\
\hline 2 & $\begin{array}{l}\text { Employees use internet, e-mail } \\
\text { and electronic bulletin boards. }\end{array}$ & 1.737 & .928 & 71 & 53.4 & 34 & 25.6 & 20 & 15.0 & 8 & 6.0 \\
\hline 3 & $\begin{array}{l}\text { Employees use the } \\
\text { organizations' intranet. }\end{array}$ & 1.692 & .906 & 75 & 56.4 & 30 & 22.6 & 22 & 16.5 & 6 & 4.5 \\
\hline 4 & $\begin{array}{l}\text { Portal is available in the } \\
\text { organization. }\end{array}$ & 2.196 & .899 & 33 & 24.8 & 51 & 38.3 & 39 & 29.3 & 10 & 7.5 \\
\hline 5 & $\begin{array}{l}\text { There is a user friendly IT } \\
\text { system. }\end{array}$ & 1.962 & .916 & 51 & 38.3 & 43 & 32.3 & 32 & 24.1 & 7 & 5.3 \\
\hline 6 & $\begin{array}{l}\text { Employees store knowledge in } \\
\text { the organizations' data base, } \\
\text { portal and intranet. }\end{array}$ & 1.872 & .865 & 54 & 40.6 & 47 & 35.3 & 27 & 20.3 & 5 & 3.8 \\
\hline 7 & $\begin{array}{l}\text { Employees store knowledge } \\
\text { on manual papers. }\end{array}$ & 2.594 & .879 & 20 & 15.0 & 29 & 21.8 & 69 & 51.9 & 15 & 11.3 \\
\hline 8 & $\begin{array}{l}\text { The organization has its own } \\
\text { website. }\end{array}$ & 2.774 & 1.03 & 24 & 18.0 & 16 & 12.0 & 59 & 44.4 & 34 & 25.6 \\
\hline 9 & $\begin{array}{l}\text { Employees should contact face } \\
\text { to face to gain information. }\end{array}$ & 2.135 & .919 & 16 & 12.0 & 18 & 13.5 & 67 & 50.4 & 32 & 24.1 \\
\hline
\end{tabular}

The second item of the questionnaire was geared towards knowing whether employees of Dashen Bank S.C of Ethiopia are using internet, e-mail and electronic bulletin boards to share their knowledge. Consequently, a majority of the respondents, i.e. $79 \%$, reported the shortage and ill-implementation of internet, e-mail and electronic bulletin boards in the organization which are in fact valuable instruments to share knowledge among each others. It should also be noted that only $21 \%$ of the respondents were in favor of utilizing these services in the organization. However, the assertion against using these services in the organization was supported by interview respondents; such as IM2, IW1, IW2, and IW5. Especially, IW2 and IW5 believed that accessing personal internet services like e-mail and facebook is strongly prohibited to use in the organization. This in turn would endanger not only the social life of the workers but also the practice of knowledge sharing within the organization.

This idea was also strengthened by the next question, requesting respondents about their experience of using organizations intranet for the purpose of sharing their knowledge to each other. However, the result revealed that most of the respondents were against the statement. Thus, about $79 \%$ of the study participants contend that the bank employees are not using the organization's intranet to share their knowledge. Same belief was also holds true to interview participants of IW1, IW2, IW4 and IW5. Besides, the availability of portal in the organization was examined by the fourth item. Accordingly, about $63.1 \%$ of the respondents suggest that portal is not available in the organization for sharing knowledge at personal level. This specific idea was also supported by IW2 and IW4. In a similar vein, however, majority of the respondents realize the organization's possession and utilization of its own website for the purpose of advocating and documenting the information regarding the activities of the bank. Thus, $80 \%$ of the questionnaire respondents recognize that the bank has its own website for documenting relevant information with regard to the program, activity, development and prospects of the organization.

Moreover, $75.9 \%$ of the respondents were against the statement which elucidate about whether they store knowledge in the organizations' data base, portal and intranet. Thus, it seems there are no data base, portal and intranet for storing personal information in the organization. Interview participants, such as IW2, IW3, IW4 and IW5, also emphasized that workers are not able to use the organization's data base, portal and intranet for private purpose, even though the personal information they store might be vital to boost the culture of knowledge sharing practices in the organization and in turn lend a hand in augmenting the performance and efficiency of the bank.

On the other hand, respondents put forward that employees are using manual papers for storing organizational information than using organizations IT systems. As tried to indicate by the seventh item of table $13,63.2 \%$ of the respondents reply that they are using manual papers for storing knowledge. According to IW2 and IW5, the use of manual papers has its drawbacks as compared to the electronic means. First, the knowledge is only private and hence not accessible to other individuals who are in need of sharing that knowledge. Secondly, 
the knowledge stored on manual paper is subjected to disappear or fade away with in short period of time before it is shared to other needy individuals.

In addition to using manual papers as means of storing and sharing knowledge, respondents were also supposed to contact face to face for exchanging information and knowledge they require. This was evidenced by the last question presented in the questionnaire. Thus, about $74.5 \%$ of the respondents declared that whenever they needs information, they have to contact the concerned person face to face than gaining the information they require through IT infrastructures. Similarly, IW2 suggested that in the absence of internet systems, there would no more than solution than to exchange information through face to face contact that the employees made during the break and week end periods.

\subsection{Knowledge Sharing Models prevailing in Dashen Bank}

This section of the result aims to detail about the models of knowledge sharing that are practiced in Dashen Bank . To this specific study, the SECI (Socialization, Externalization, Combination and Internalization) model was chosen as a framework because of the aforementioned reasons. Based on this model, an instrument (having 11 items) was developed with the aim of knowing which mode of SECI model predominantly practiced in the organization. Thus, the result is analyzed descriptively using frequencies and percentages relying table 14 below. As clearly depicted in the table, about $69.2 \%$ of the respondents suggest that they are not involving in knowledge management activities; such as in delivering orientations, monitoring and coaching the newly recruited employees of the organization. However, the majority of the respondents, i.e. $51.8 \%$, believed that their staff colleagues are willing to share knowledge with themselves. A 2.609 mean score to this statement also strengthen the assertion that most employees have the willingness to share knowledge among themselves. Nonetheless, a massive amount of the respondents $(76.6 \%)$ are not sharing information and knowledge valuable to the organization either before or after regular working hours.

Table 7: Knowledge sharing at Socialization mode of SECI model

\begin{tabular}{|c|c|c|c|c|c|c|c|c|c|c|c|}
\hline \multirow[b]{3}{*}{ No. } & \multirow[b]{3}{*}{ Items } & \multirow[b]{3}{*}{ Mean } & \multirow[b]{3}{*}{ SD } & \multicolumn{8}{|c|}{ Response Alternatives } \\
\hline & & & & \multicolumn{2}{|c|}{ Not at all } & \multicolumn{2}{|c|}{ Rarely } & \multicolumn{2}{|c|}{ Usually } & \multicolumn{2}{|c|}{ Always } \\
\hline & & & & Freq. & $\%$ & Freq. & $\%$ & Freq. & $\%$ & Freq. & $\%$ \\
\hline 1 & $\begin{array}{l}\text { I am involved in } \\
\text { knowledge } \\
\text { management } \\
\text { activities, e.g. in } \\
\text { monitoring and } \\
\text { coaching activities } \\
\text { for new entrants. }\end{array}$ & 2.023 & 1.0834 & 57 & 42.9 & 35 & 26.3 & 22 & 16.5 & 19 & 14.3 \\
\hline 2 & $\begin{array}{l}\text { Colleagues are } \\
\text { willing to share } \\
\text { any knowledge } \\
\text { with me. }\end{array}$ & 2.609 & .9198 & 14 & 10.5 & 50 & 37.6 & 43 & 32.3 & 26 & 19.5 \\
\hline 3 & $\begin{array}{l}\text { Staff members } \\
\text { share knowledge } \\
\text { before and after } \\
\text { regular working } \\
\text { hours. }\end{array}$ & 1.936 & .9033 & 49 & 36.8 & 53 & 39.8 & 21 & 15.8 & 10 & 7.5 \\
\hline
\end{tabular}

The third item was also tried to be triangulated by an interview question developed to examine whether workers interact to each other before and after working hours for sharing information and knowledge. To this end, IM2, IW3, IW4 and IW5 contend that most of the workers do not have the habit of discussing and exchanging information during these sparse times. According to them, employees usually do not pass times together after work hours, but even if there might be a chance to interact among themselves, the agenda more likely treated is very private than issues related to their organization and field of work.

Socialization is an important aspect of knowledge sharing in organizations. In this mode of knowledge sharing, the tacit knowledge is shared either internally or externally (Glisby and Holden, 2003). An internal knowledge sharing could be done through employees' strong personal affiliation and commitment to the organization they work, with the cooperative attitudes created among employees themselves as well as through developing an intimate relationships with those who are intended to share the knowledge. However, knowledge sharing cannot be effective with the implementation of internal knowledge sharing alone. Knowledge should also be shared externally. By external sharing, outdoor agents and think thanks could share their acquaintance and knowledge to the organization. This could be done by facilitating formal and informal meetings outside of the work place, where tacit knowledge such as world views, paradigms, philosophies, emerging theories, 
contemporary practices, etc. could be shared. Besides, organizations could also be benefited by enhancing their effort to exploit the knowledge and experiences of their customers, stakeholders, suppliers, government officials, etc. (Nonaka et al., 2000).

Table 8: Knowledge sharing at Externalization mode of SECI model

\begin{tabular}{|c|c|c|c|c|c|c|c|c|c|c|c|}
\hline \multirow[b]{3}{*}{ No. } & \multirow[b]{3}{*}{ Items } & \multirow[b]{3}{*}{ Mean } & \multirow[b]{3}{*}{ SD } & \multicolumn{8}{|c|}{ Response Alternatives } \\
\hline & & & & \multicolumn{2}{|c|}{ Not at all } & \multicolumn{2}{|c|}{ Rarely } & \multicolumn{2}{|c|}{ Usually } & \multicolumn{2}{|c|}{ Always } \\
\hline & & & & Freq. & $\%$ & Freq. & $\%$ & Freq. & $\%$ & Freq. & $\%$ \\
\hline 5 & $\begin{array}{l}\text { I raise my ideas on } \\
\text { discussions } \\
\text { workshops. }\end{array}$ & 2.128 & .9567 & 40 & 30.1 & 49 & 36.8 & 31 & 23.3 & 13 & 9.8 \\
\hline 6 & $\begin{array}{l}\text { I usually share my } \\
\text { ideas and knowledge } \\
\text { with colleagues using } \\
\text { charts and pictures or } \\
\text { written form. }\end{array}$ & 1.571 & .8728 & 84 & 63.2 & 29 & 21.8 & 13 & 9.8 & 7 & 5.3 \\
\hline
\end{tabular}

Regarding the practice of the Externalization mode of the SECI model, which implies converting tacit knowledge into explicit one, the researcher made an attempt to treat the issue by designing two interrelated items, as shown in table 15 . Accordingly, about $66.9 \%$ of the respondents believed that they have difficulty of raising their ideas during meetings, discussions, trainings and workshops organized by the organization. Similarly, a huge amount of the respondents $(85 \%)$ witnessed that they are reluctant to share their ideas and knowledge with their colleagues in either of communication medias such as through charts, figures, pictures of in written form.

Furthermore, with regard to the first item of the externalization phase, the interview respondents were found to raise ideas from both sides. Thus, IM4, IW1 and IW3 reply that they are active in participating as well as raising ideas during workshops and meetings where as interviewee such as IW2 and IW4 were against this contention. The later believed that fear and lack of confidence among themselves and workers of the organization are the major causes behind the passive participation of workers in meetings and workshops. They adds; workers choose to discuss on issues privately than making it explicit during meetings and discussions.

It should be known that externalization is a fundamental phase to heighten the social interactions and information exchanges of employees of an organization. According to Nonaka et al. (2000), of the four modes of knowledge conversion, externalization is the key to knowledge creation because it creates new, explicit knowledge from individuals' tacit knowledge. It is believed to be a vital phase for building the culture of knowledge sharing practices in an organization. When tacit knowledge is made explicit, knowledge is crystallized, thus allowing it to be shared by others, and it becomes the basis of new knowledge (Konno et al., 2005).

During face to face or internet communication, people share their knowledge and beliefs and learn how to better articulate their thinking in light of their colleagues (Spencer, 2005). However, Nonaka and Takeuchi (1995) stress that this stage of the model is the most difficult and time-consuming one, and emphasize the importance of organizational and individuals' commitment for its realization. This mode requires the organization to facilitate situations, such as get together, trainings, workshops, seminars, etc. so that employees could interact and share their tacit knowledge and make it explicit to others. On the other hand, individuals should also be committed to make explicit the tacit knowledge they accumulate before.

Table 9: Knowledge sharing at Combination mode of SECI model

\begin{tabular}{|c|c|c|c|c|c|c|c|c|c|c|c|}
\hline \multirow{3}{*}{$\begin{array}{l}\text { Item } \\
\text { No. }\end{array}$} & \multirow[b]{3}{*}{ Items } & \multirow[b]{3}{*}{ Mean } & \multirow[b]{3}{*}{ SD } & \multicolumn{8}{|c|}{ Response Alternatives } \\
\hline & & & & \multicolumn{2}{|c|}{ Not at all } & \multicolumn{2}{|c|}{ Rarely } & \multicolumn{2}{|c|}{ Usually } & \multicolumn{2}{|c|}{ Always } \\
\hline & & & & Freq. & $\%$ & Freq. & $\%$ & Freq. & $\%$ & Freq. & $\%$ \\
\hline 7 & $\begin{array}{l}\text { Documentations are } \\
\text { up to date in my } \\
\text { bank. }\end{array}$ & 2.857 & 1.0599 & 18 & 13.5 & 31 & 23.3 & 36 & 27.1 & 48 & 36.1 \\
\hline 8 & $\begin{array}{l}\text { New manuals are } \\
\text { prepared frequently } \\
\text { in my bank. }\end{array}$ & 2.601 & .9687 & 18 & 13.5 & 45 & 33.8 & 42 & 31.6 & 28 & 21.1 \\
\hline 9 & $\begin{array}{l}\text { In my banks, new } \\
\text { procedures and } \\
\text { manuals distributed } \\
\text { quickly. }\end{array}$ & 2.564 & 1.0398 & 25 & 18.8 & 38 & 28.6 & 40 & 30.1 & 30 & 22.6 \\
\hline
\end{tabular}

Unlike the two phases discussed before, respondents' reaction to items of combination phase is in favor of it. As shown in table 16, respondents report the well presence of this mode in the bank than others. That means, explicit knowledge is shared among individuals appropriately via a documentation form. Specifically, about 
$63.2 \%$ of the respondents report that various documentations of the bank are up to date and timely. $52.7 \%$ of the respondents also believed that new manuals are frequently prepared that are vital to boost up the efficiency of the organization. Similarly, those prepared manuals, brochures, pamphlets and procedures enacted are also distributed to the concerned office or individual quickly. Like the previous one, this idea is also supported by $52.7 \%$ of the respondents.

Table 10: Knowledge sharing at Internalization mode of SECI model

\begin{tabular}{|c|c|c|c|c|c|c|c|c|c|c|c|}
\hline \multirow[b]{3}{*}{ No. } & \multirow[b]{3}{*}{ Items } & \multirow[b]{3}{*}{ Mean } & \multirow[b]{3}{*}{ SD } & \multicolumn{8}{|c|}{ Response Alternatives } \\
\hline & & & & \multicolumn{2}{|c|}{ Not at all } & \multicolumn{2}{|c|}{ Rarely } & \multicolumn{2}{|c|}{ Usually } & \multicolumn{2}{|c|}{ Always } \\
\hline & & & & $\begin{array}{c}\text { Fre } \\
\text { q. }\end{array}$ & $\%$ & $\begin{array}{c}\text { Fre } \\
\text { q. }\end{array}$ & $\%$ & $\begin{array}{c}\text { Fre } \\
\text { q. }\end{array}$ & $\%$ & Freq. & $\%$ \\
\hline 4 & $\begin{array}{lr}\text { Training } & \text { programs, } \\
\text { workshops } & \text { and } \\
\text { seminars } & \text { are } \\
\text { frequently } & \text { organized } \\
\text { for the staff. }\end{array}$ & 1.993 & .8659 & 42 & 31.6 & 58 & 43.6 & 25 & 18.8 & 8 & 6.0 \\
\hline 10 & $\begin{array}{l}\text { The bank frequently } \\
\text { allows for } \\
\text { postgraduate or other } \\
\text { professional training } \\
\text { for staff members. }\end{array}$ & 1.895 & $\begin{array}{c}1.046 \\
4\end{array}$ & 64 & 48.1 & 35 & 26.3 & 18 & 13.5 & 16 & 12.0 \\
\hline 11 & $\begin{array}{l}\text { I use the knowledge } \\
\text { acquired in training } \\
\text { and workshop. }\end{array}$ & 2.436 & $\begin{array}{c}1.017 \\
7\end{array}$ & 28 & 21.1 & 43 & 32.3 & 38 & 28.6 & 24 & 18.0 \\
\hline
\end{tabular}

The fourth mode of the SECI model is internalization. Internalization is the process of understanding and absorbing explicit knowledge in to tacit knowledge held by the individual. At this mode, workers are expected to acquire knowledge using different means of knowledge gaining. However, the result is found to be a mere satisfactory, as plainly depicted in table 17. Majority of the respondents were against the presence of internalization phase in the organization. Particularly, $75.2 \%$ of the respondents witnessed that major knowledge gaining circumstances such as training programs, workshops and seminars are not organized for the staff regularly. As a result, majority of the respondents (53.4\%) are not fortunate to use the knowledge that could be acquired through these means. The bank is not also facilitating scholarships for those who are in need of escalating their educational level and their knowledge in turn. This contention was supported by about $74.3 \%$ of the respondents.

The internalization mode is another vital instrument of transferring knowledge from organization and group explicit knowledge to the individual. The individual could acquire these knowledge through trainings, workshops or scholarships the organization facilitates to the workers. The human's reasoning process of finding insights could be made possible by the internalization mode of the SECI model (Wang et al., 2009). Unless workers updated their knowledge through these means, they cannot be active in the process of knowledge sharing practice and in turn build a positive view towards exchanging knowledge among the staff members. That is why this phase of knowledge sharing practice is regarded as basic to the development of socialization, externalization and combination modes of knowledge sharing (Nonaka\& Takeuchi, 1995).

So far, an attempt was made to present the results obtained at a mode level. Hence, a result of the items of each respective mode was analyzed appropriately. However, one major objective of this study was to identify which mode of the SECI model is predominantly overwhelming the knowledge sharing practices of Dashen Bank . To this end, a comparative analysis is made among the four phases relying on the grand mean scores of each item of the phases. Table 18 clearly presents the grand mean scores of each phase of the SECI model.

Table 11: Grand mean scores of the SECI model phases

\begin{tabular}{lcccc} 
& \multicolumn{4}{c}{ Modes of the SECI Model } \\
\cline { 2 - 5 } Grand mean score & Socialization & Externalization & Combination & Internalization \\
\hline
\end{tabular}

As seen in the above table, the highest score is reported in the combination phase (mean $=2.674)$ whereas the lowest score was observed in externalization phase (1.849). Thinking the 2.50 mean score of the scales, only the combination phase is found to be slightly higher than the mean score. The grand mean scores of socialization and internalization was 2.189 and 2.108 respectively. Thus, the result indicated that the bank is dominantly practicing the combination mode of the SECI model. This is to mean that the bank is relatively efficient at converting the explicit knowledge of the organization into more systematic sets of explicit knowledge through different means such as books, papers, brochures, pamphlets, etc. On the other hand, externalization was found to be the least practiced phase of the SECI model. Hence, the bank is in a deprived position at converting the 
tacit knowledge of the workers into an explicit one using suitable mechanisms that are reachable to the remaining workers of the organization. The socialization and internalization phases, though relatively better than externalization, are also phases poorly implemented in the bank.

The central thought of the SECI model was the fact that knowledge held by individuals is shared with other individuals so that it interconnects to a new knowledge. Specifically, combination is the process of converting explicit knowledge into more complex and systematic sets of explicit knowledge (Wang et al., 2009). In the combination phase, the explicit knowledge, that exists in the form of books, pamphlets, brochures, research papers, and communication networks, could be collected from inside or outside the organization and then combined, edited or processed to form a new knowledge. The new explicit knowledge is then disseminated among the members of the organization by facilitating an appropriate environment for gaining the knowledge.

Besides, computerized communication networks and large-scale databases could also facilitate the mode of knowledge conversion at the combination phase (Nonaka, et al., 2000). Thus, combination allows knowledge transfer among staff members in organizations more pragmatic and long lived. Thus, Dashen Bank S.C could be benefited more by preserving the high tradition of practicing the combination mode of the SECI knowledge sharing model, in fact by giving further emphasis to improve the internalization, externalization and socialization modes of knowledge sharing and information exchange.

\section{CONCLUSIONS AND RECOMMENDATIONS}

\subsection{Conclusions}

The study exposed a difference in knowledge sharing practice among different groups of workers. For instance, females and the young were better in their knowledge sharing practice than males and older workers respectively. It seems that males and older employees need extra intervention mechanisms in order to boost their practice to knowledge sharing. Similarly, those with lower education level and with greater worker experience had a poor attitude towards knowledge sharing and in turn creating a better atmosphere of knowledge sharing. Thus, trainings and workshops on how to access the diverse information communication mechanisms that enhance their knowledge sharing practices seems inevitable. In fact, if the organization's emphasis is on the potentials of knowledge sharing practice of workers, focusing on females and the less experienced ones is beneficial while hiring, as it is evidenced by their strong impact on knowledge sharing practice.

With regard to the barriers that play a debilitating role on employees knowledge sharing practices, lack of rewards and recognition systems, workers' lack of time to share knowledge, employees' low motivation of sharing knowledge, scarcity of IT infrastructures, lack of formal and informal awareness creating activities, lack of interaction among the staff members, poor physical work environment and office layouts, and poor interpersonal and communication skills were the major ones. Thus, unless there is an environment of work where these influential factors are eased, the organizations' culture of knowledge sharing could not be improved to the extent it is expected to be. Especially, the organization has to furnish itself with the necessary IT infrastructures so that its employees could access it whenever they are in need of sharing knowledge among themselves. The organizations should also look back again and check how knowledge is shared among their employees. Literatures evidenced that being efficient at implementing the four modes of the SECI models of knowledge sharing is vital to create a better culture of knowledge sharing in an organization. However, this finding revealed that combination is the only mode better implemented in the bank. Even though the implementation of the combination mode of knowledge sharing is appreciated, being reluctant at availing the socialization, internalization and externalization modes has a detrimental effect.

\subsection{Recommendations}

Based on the findings attained and conclusions made, the following recommendations are forwarded to the concerned bodies that are responsible to create a better culture of knowledge practice in the Dashen Bank S.C of Ethiopia.

First, comparatively speaking, employees who were male, highly experienced, older and with lower education level had a lower view towards sharing knowledge with each others. Thus, the organization should facilitate environments such as trainings, workshops, seminars, discussions, meetings etc so that the awareness of these individuals towards the importance of knowledge sharing is escalated. Moreover, the organization should also encourage its employees to take either formal or informal trainings that play a great role in developing their skills of accessing different information communication technology infrastructures.

The fundamental role of equipping the organizations with the necessary ICT infrastructures such as internet, intranet, web portals, data base, information repository, etc should not only be seen in light of their importance for storing and retrieving organization's information, but they should also be planted for the purpose of communication and sharing knowledge as well. Employees should have a full access of ICT infrastructures to their knowledge among the staff members.

Another influential barrier to the knowledge sharing practice was found to be the employees' lack of time 
and low motivation to share knowledge among their colleagues. Thus, the organization should create an environment of enhancing employees' awareness about the importance of knowledge sharing so that they could give adequate amount of time and energy for sharing knowledge. Besides, the organization should also enact rules and regulations that oblige employees to put their knowledge in to different explicit data formats such as portals, data base, information repository and the like.

Moreover, poor physical work environments and office layouts were also mentioned as a determinant factor for employees' lower levels of knowledge sharing practices in their respective organizations. Hence, the organizations should reframe the sitting arrangements, office layouts, office furniture etc. in order to create an office environment comfortable to share knowledge among the employees themselves. By doing so, the organization could also boost the social relationships and interactions of the employees, which in turn is vital to knowledge sharing practices.

Regarding the modes of knowledge sharing practices applied in the organization, internalization, socialization and externalization modes of the SECI model were the least practiced among the employees of the banks. Therefore, the organizations should adjust environments for employees to exchange their knowledge via these modes of knowledge conversion. Especially, the organization should develop the culture of knowledge conversion from tacit to explicit as it enable the employees to create new explicit concepts and knowledge related to the field of their work and organizations.

Finally, the researcher would like to recommend other researchers to conduct further study on the area in depth and breadth. To this end, this study might generate an interest and assist as a stepping stone for them.

\section{REFERENCES}

Al-Alawi, A. I., Al-Marzooqi, N. Y., and Mohammed, Y. F. 2007. Organizational culture and knowledge sharing. Journal of knowledge management, n11 (2): 22-42, Emerald Group Publishing Limited, ISSN 1367-3270. DOI 10.1108/13673270710738898.

Bellinger, G., Castro, D., and Mils, A. 2007. Data, information, knowledge, and wisdom. Journal of knowledge management, n11 (4): 5-7.

Bernstein, J. H. 2009. The Data-Information-Knowledge-Wisdom Hierarchy and its Antithesis. Proceedings North American Symposium on Knowledge Organization V (2). (URL: http://www.dlist.sir.arizona.edu/2633/.) Accessed on Feb 11, 2014.

Borghoff, U. M. 2007. Information technology for knowledge management. Rank Xerox Research Centre, Grenoble Laboratory, Meylan, France.

Bornemann, M., Graggober, M., and Hartilleb, E. 2003. An illustrated guide to knowledge management.Asean foundation, Jekareta, Indonesia.

Cheng M.Y, Ho J, S. Y, and Lau P. M. 2011. Knowledge Sharing in Academic Institutions: a Study of Multimedia University Malaysia. Electronic Journal of Knowledge Management n3(7) :313 - 324. (URL: http://www.ejkm.com.)

Creswell, J. W. 2008. Research design: Qualitative, quantitative and mixed methods approach ( $\left.{ }^{\mathrm{rd}} \mathrm{ed}.\right)$. Thousand Oaks, CA: Sage publications.

Dalkir, K. 2005. Knowledge management in theory and practice. McGill University, Elsevier ButterworthHeinemann, 1-372. Accessed on Feb 28, 2014.

Glisby, M., Holden, N. 2003. Contextual constraints in knowledge management theory: the cultural embeddedness of Nonaka's knowledge-creating company, Knowledge \& Process Management, n1 (10): 2936.

Gourlay, S. 2004. The SECI model of knowledge creation: some empirical shortcomings: Knowledge management practice and research, URL: http://www.secimodelgourlay2341.pdf. Accessed on Nov 14, 2013.

Gurteen, D. 1999. Creating knowledge sharing culture. Knowledge Management Magazine, n2 (5):1-78.

Habtamu Mohammed. 2011. Evaluation of knowledge sharing practice in commercial bank of Ethiopia. Master's thesis, Addis Ababa University, Addis Ababa, Ethiopia.

Hareya G/ Selassie, 2011. Knowledge sharing among employees of Mesfin Industrial Engineering. Master's Thesis, Addis Ababa University, Addis Ababa, Ethiopia.

Hayati, S, and Nor, L. 2006. Behind the Scenes of Knowledge Sharing in Japanese Bank, Human Resource Development International, n4 (4): 465 - 485.

Hendriks, P. 1999. Why share knowledge? The influence of ICT on the motivation for knowledge sharing. Journal of knowledge and process management, n6 (2): 91-100.

Human Resource Development International (HRDI). 2001. Knowledge management and knowledge sharing process in an organization.

International Fund for Agricultural Development (IFAD). 2007. Knowledge management strategy: Enabling poor rural people to overcome poverty. Via del Serafico, Rome. 
Ismail, M. B. and Yusof, Z. M. 2009. Demographic factors and knowledge sharing quality among Malaysian government officers. Communications of the IBIMA Volume 9, 2009 ISSN: 1943-7765.

Jashapara, A. 2004. Knowledge Management: An integrate approach. Halow, Essex Prentice Hall, New York, NY.

Kamasak, R., and Yucelen, R. 2010. The relationship between knowledge assets and organizational strategy development. International Journal of Business and Management Studies, n2 (2): 65- 71.

Kridan, A. and Goulding, S.2006.A Case Study on Knowledge Management Implementation in the Banking Sector. The Journal of Information and Knowledge Management Systems, n2 (36).

Liew, A. 2013. DIKIW: Data, information, knowledge, intelligence, wisdom and their interrelationship. Business management dynamics, n10 (2): 49-62.

(URL: www.bmdynamics.com ). Accessed on Nov 22, 2013.

Micheal Geze. 2011. The history of banking and other financial institution in Ethiopia. (URL: http://www.scribd.com/doc/17055376/The-History-of-Banking-inEthiopia ). Accessed on October 12, 2013.

Miller, D. L. and Karakowsky, L. 2005. Gender influences as an impediment to knowledge sharing: When men and women fail to seek peer feedback, Journal of Psychology, n138: 101- 118.

Nonaka, I. 1991. The Knowledge Creating Company, Harvard Business Review, 11: 96 - 104.

Nonaka, I. and Konno, N. 1998. The concept of 'Ba': building a foundation for knowledge creation', California Management Review, n 3(40): 40-54.

Nonaka, I. and Takeuchi, H. 1995. The knowledge creating company: How Japanese company create the dynamics of innovation. New York: Oxford University Press.

Nonaka, I., and Krogh, G. V. 2009. Tacit knowledge and knowledge conversion: Controversy and advancement in organizational knowledge creation theory. Organization Science, n3 (20): 635-652, DOI: 10.1287/orsc.1080.0412. Accessed on Feb 3, 2014

Nonaka, I., Krogh, D. V. and Voelpel, S. 2006. Organizational knowledge creation theory: Evolutionary paths and future. DOI: 10.1177/0170840606066312. Accessed on Sep 21, 2013.

Nonaka, I., Toyama, R., and Konno, N. 2000. SECI, Ba and leadership: a unified model of dynamic knowledge creation, Long Range Planning, n1 (33): 8-17.

Pangil, F. and Nasrudin, A. M. 2008. Demographic factors and knowledge sharing behaviors among R\&D employees. Knowledge management international conference (KMICE), Langkawi, 128-133.

Rasoulinezhad, E. 2011. Measuring the role of knowledge management processes in the commercial banks of Iran. The Electronic Journal of Knowledge Management , 9 (4) :353-364. (URL:www.ejkm.com ). Accessed on August 8, 2013.

Riege, A. 2005. Three-dozen knowledge-sharing barriers managers must consider. Journal of Knowledge Management, n9 (3): 18-35. DOI: 10.1108/13673270510602746. Accessed on Dec 23, 2013.

Smith, R. D., and Bollinger, A. S. 2001. Managing organizational knowledge as a strategic asset. Journal of Knowledge Management, n5 (1): 8-18.

Spencer, B. 2005. At the Knowledge advantage. A presentation by Dr. Ikujiro Nonaka, conference held on November 11-12, 1997, National Security Agency.

Spender, J. C. 1996. Making knowledge the basis of a dynamic theory of the Firm. Strategic Management Journal, 17: 45-62.

Wang, S. and Noe, R. A. 2010. Knowledge sharing: A review and directions for future research. Journal of Human Resources Management, 20: 115-131.

Wang, X., Jeong, D. H., Dou, W., Lee, S. W., Ribasky, W., and Changapril, R. 2009. Defining and applying knowledge conversion processes to a visual analytics system. Journal of Management Issues, n 2 (23): 33 67. 